УДК 821.161.1

DOI: 10.12731/2077-1770-2017-4-171-180

\title{
ОБ ОСОБЕННОСТЯХ КОМПОЗИЦИИ ПРОЗАИЧЕСКИХ ПРОИЗВЕДЕНИЙ И ИДИОСТИЛЕ ПИСАТЕЛЯ
}

\section{Мартазанов А.М.}

Цель. В статье рассматриваются композиционные особенности прозачческих произведений писателей, одновременно являюшиихся и поэтами. Актуальность исследования состоит в изучении своеобразия структуры литературы национальных писателей, в том числе и русскоязычных, определении разнообразия стилистических средств при создании художественных образов, характера повествования. Речь автора и речь персонажа рассматриваются в качестве двух самостоятельных типов изложения, так как различаются в композиционных, содержательных и формальных признаках. На материале художественных произведений современных писателей показано, что авторская позииия наиболее эксплицитно проявляется в собственных высказываниях, а точка зрения персонажа - в его речи, которая имеет языковые различия на всех уровнях.

Метод или методология проведения работы. При исследовании применялись описательный и сопоставительный методы.

Результаты. Результаты исследования уточняют вопросы формирования своеобразия нарративного дискурса и узнаваемого идиостиля писателя национальной литературы.

Область применения результатов. Результаты исследования могут быть применены при изучении композиционных особенностей художественного произведения северокавказских литератур в вузе и школе.

Ключевые слова: проза; композиция; стилистические средства; язык художественного произведения. 


\section{ON THE COMPOSITION PECULIARITIES OF THE WRITER'S PROSE AND INDIVIDUAL STYLE}

\section{Martazanov A.M.}

Purpose. The article deals with compositional features of prose works of writers, who are also poets. The relevance of the research is to study the peculiarities of the structure of the national writers' works, including Russian-speaking ones, to determine the diversity of stylistic means in the creation of artistic images and the nature of the narrative. The author's speech and the character's speech are considered as two separate types of presentation, as they differ in compositional, content and formal features. Based on the material of the works of contemporary writers, it is shown that the author's position is most explicitly expressed in their own statements, and the point of view of the character is in their speech, which has linguistic differences at all levels.

Methodology. The study used descriptive and comparative methods.

Results. The results of the study clarify the issues of identity formation in narrative discourse and recognizable style of the writer of the national literature.

Practical implications. The results of the study can be used to study compositional features of works of art of the North Caucasian literatures in the University and the school.

Keywords: prose; composition; stylistic means; language of the work of art.

Наиболее неоднозначно трактуемым понятием из всех доминантных терминов науки о литературе, до настоящего времени не получившимодносложной и недвусмысленной дефиниции в филологических исследованиях,представляет собой композиция, под которой, в зависимости от преобладающей точки зрения, понимают или структурные характеристики литературного произведения, или последовательность описания деталей и персонажей, или элементы лингвистического описания художественного текста и т.д.

Прозаические произведения писателей, которые наряду с этим пишут и стихи, отличаются особым характером нарративного дискурса 
и своеобразными способами формирования узнаваемого идиостиля писателя. Так, например, М. Цветаева свои прозаические произведения относила к работе поэта, подчеркивая неразрывную связь стиха и прозы в своем творчестве. Данная особенность обусловлена спецификой поэтического мышления писателя, который даже в прозаическую речь переносит приемы стихотворной организации.

Писатель выстраивает композицию произведения с учетом собственных ассоциативных связей между структурными частями, иногда спешно меняя событийную канву и переходя на фрагментарное изложение сюжетной линии, что делает ритмически своеобразным и узнаваемым язык и стиль автора.

Разбивая свой текст на главы, писатель должен, очевидно, задумываться о его органичности, о жанре, в котором написано произведение, над оригинальностью формы (хотя это в меньшей степени, чем два других), о супрасегментных единицах, влияющих каким-нибудь образом на ритмику текста, и на многое другое (как в сценарии сериала, учитывая временной отрезок, место действия, участников нарративного дискурса и т.д.). В таких случаях автор не берет во внимание, по большей части, размер отрывка, выделяемого в отдельный раздел, поэтому текст может состоять даже из нескольких предложений.

В качестве примера, подтверждающего данную гипотезу, приведем выдержки из произведений некоторых писателей-поэтов Северного Кавказа. В осетинской литературе ярким примером доминирования ритмики поэтического характера в прозаическом произведении может служить роман С. Хугаева «Нарт Фарнаг», в котором певучесть и ритмичность намеренно акцентируются для того, чтобы придать произведению характерный для эпического повествования «стихотворный» размер: «Ноджы цыдæр æнахуыр парахат худт кодта Уастырджи, цыма фыдæнæн афтæ худти, уыйау йæ урс-урсид даргъ дæндæгтæн сæ рæбынтæ дæр разындысты суанг» - «Да еще как-то необычно широко улыбался Уастырджи, как будто назло смеялся так, что верхушки его белых-белых зубов показались даже» (перевод наш - А.М.) [13, с. 78]. 
В этом предложении использована инверсия, без применения которойэто был бы обычный повествовательный ритм, какой характерен для любого другого прозаического текста, об оригинальности такого текста не было бы и речи $[2,7]$.

В романе мы видим множество повторов однокоренных лексических единиц, создающих такой же особый ритм. По мнению Л.Б. Гацаловой и Л.К. Парсиевой, «повтор является не только одним из средств организации ретроспекции и проспекции в тексте, но и способом выражения субъективной модальности. Эстетический и экспрессивный эффект повтора значительно возрастает при использовании разных видов дублирования: фонетико-фонологического, лексического, морфемно-морфологического, семантического и синтаксического. Характер повторов и их функциональная нагруженность напрямую зависят от жанровой разновидности текста художественного произведения. В авторском тексте повествовательно-рассуждающего характера они в основном выполняют модально-экспрессивную функцию, а в текстах описательного характера выражают субъективно-авторское отношение к изображаемому» [1, с. 101].

Творческий «багаж» поэта, система эмоционально-экспрессивных средств, имеющихся в его арсенале, непосредственно влияет на характер композиционных составляющих художественного прозаического произведения. Так, отмечается использование «поэтических» средств в прозе русскоязычного осетинского писателя-поэта И. Хугаева (к примеру, в его повести «Изгой»): «Куда бы ты ни шёл - ты идешь к своей могиле. Ты идёшь к ней, даже когда сидишь на месте, в своей пещере. В пространстве нет пути, есть только суетное перемещение; время и есть истинный путь; здесь нельзя ни свернуть, ни вернуться.

Есть только ты и твоё время, твой путь. Не ты идешь своим путём: твой путь проходит через тебя. Как нить, вдетая в игольное ушко, скользит сквозь тебя твой путь, твоё время [11, с. 23].

В данной повести такой поэтический этюд, выделенный в отдельный раздел, - не единичное явление, не вкрапление в основной сюжет; из таких этюдов автор и строит свое произведение, которое обладает, благодаря особой поэтической ритмике, совершенно неповторимым идиостилем. 
Общепринятое суждение о ритме хорошо сформулировано в высказывании: «В каждом образе присутствует то, что можно назвать «ритмом», «пропорцией» и «гармонией».Ритм возникает из более или менее размеренного повторения звуков, цветов, форм и движений. Пропорция - это такое воплощение замысла художника, которое кажется нам правильным, выраженным в соизмеримых частях. Гармония заключается в естественном соответствии различных частей образа друг другу» [10, с. 9]. Действительно, ритм и гармония прозы писателя, который одновременно является еще и поэтом, схожи с музыкальным ритмом и гармонией, без которых не может существовать композиция. То есть, одна их основ композиции художественного произведения - это его ритм, соединенный с гармонией, даже если это прозаическое произведение. Как в романе уже получившего признание современного чеченского писателя С. Яшуркаева «Ях. Дневник чеченского писателя»: «У чеченцев есть слово из двух букв: «ях». Оно означает и героизм, и гордость, и честь, и благородство, и силу, и дерзость, и еще что-то, что легко понимает семилетней ребенок в самом глухом чеченском ауле, но трудно понять тем, кто сбрасывает сейчас бомбы на этого ребенка. Особое состояние не только души, но и тела: глубоко сознательная, радостная готовность претерпеть все, но совершить то, что должно быть совершено. Все высшие человеческие качества уложены в этом слове. Каждый день вижу парней с оружием - одни идут в бой, другие выходят из боя. На их лицах улыбки, и эти улыбки не показные и не вымученные. Они в состоянии ях. Ях - путь человека от рождения до подвига и достойной смерти, до высшей точки духовного и физического подъема. Триста спартанцев у Фермопил, безусловно, были в состоянии “ях"» [16].

Изобилие фигур речи, вполне уместных в данном фрагменте, особая структура предложений, создающие своеобразный стихотворный ритм, являются «визитной карточкой» индивидуального стиля С. Яшуркаева не только в его первом литературном опыте, но и в последующих, например, в романе «Царапины на осколках»:«Пришедшую мысль - гонишь, ушедшую - ищешь. Как сорвавшаяся с цепи собака, убежала очередная. Спохватываешься догнать ее. 
Затерявшись в джунглях одеревеневшей головы, она становится важной, что-то решающей. Воображаешь, что в поисках ее вынул из себя душу и ищешь в ее потемках. Душа оказалась и не “потемками”, и не яркой - небольшой слабо просвечивающий ком, похожий на уменьшенную луну, когда смотришь на нее в перевернутый бинокль, с такими же темноватыми пятнами, расползшимися по поверхности. Кладешь на ком ладонь и мягким глиняным шариком катаешь его по клетчатой клеенке кухонного стола. Он не то шуршит каким-то липучим шепотом, похожим на стон пожелтевшей листвы, угнетаемой осенним ветром, не то издает скрипучие звуки старого дерева, раскачиваемого тем же ветром. Катая этот не холодный, но давно и не горячий предмет, пытаешься вспомнить, зачем вынимал его. Мысль нашлась, “привязал” ее. Оказалась ничего не решающей, ничем не мудрой, все той же - вести записи, как и в прошлую войну. Ком под ладонью сжался и куда-то провалился - участвовать в этом он не желает» [15].

Здесь можно вспомнить о прозе турецкого писателя А.Х. Танпынара, которую также отличает стихотворная эстетика: «На его творчестве как прозаика постоянно отражались занятия поэзией», пишет А.И. Пылев [9, с. 54].

Очевидно, что, даже когда в произведении писателя, который одновременно является автором поэтических текстов, затрагиваются общественно значимые и актуальные для современного социума проблемы, его слог не становится менее образным, никуда не уходит и привычная стихотворная ритмика, и обилие тропов, потому что на первый план такие писатели выдвигают эстетику как основу искусства слова. Именно это и отличает композицию и архитектонику прозы мастеров поэтического жанра.

\section{Список литературы}

1. Гацалова Л.Б., Парсиева Л.К. Повтор как выразительное средство языка художественного произведения // Вестник Томского государственного педагогического университета. 2016. № 11 (176). С. 101-104.

2. Гацалова Л.Б., Парсиева Л.К. Современный русско-осетинский раз- 
говорник. Владикавказ: ИПО СОИГСИ, 2013. 143 с.

3. Гацалова Л.Б., Парсиева Л.К. Социально-аксиологические ориентиры современного российского общества // В мире научных открытий. 2013. № 11.6 (47). С. 28-31.

4. Мартазанов А.М., Мартазанова Х.М. Становление жанра повести в ингушской прозе 1950-х-1960-х годов // Мир науки, культуры, образования. 2016. № 4 (59). С. 203-205.

5. Мартазанова Х.М. Осмысление судьбы творческой личности в художественном мире И. Базоркина // Мир науки, культуры, образования. 2015. № 4 (53). С. 318-320.

6. Мартазанова Х.М. Повесть А. Бокова «Буран» как значительное явление ингушской прозы 60-х годов XX века // Научное мнение. 2015. № 11-1. С. 152-155.

7. Парсиева Л.К., Гацалова Л.Б. Производные междометия: к вопросу о вербализации эмоций // Балтийский гуманитарный журнал. 2016. Т. 5. № 3 (16). С. 66-68.

8. Пастушкова Н.А. Риторико-стилистические особенности испанских сентиментальных повестей: от поэзии к прозе // В-к РГГУ. Серия: История. Филология. Культурология. Востоковедение. 2010. № 11 (54). С. 90-96.

9. Пылев А.И. Ахмед Хамди Танпынар и его роман «Спокойствие». О некоторых стилистических особенностях формы и содержания произведения // Вестник Санкт-Петербургского университета. Серия 13. Востоковедение. Африканистика. 2011. № 4. С. 51-65.

10. Ситников В.П., Шалаева Г.П., Ситникова Е.В. Кто есть кто в мире искусства / Под общ. ред. В.П. Ситникова. М.: АСТ, СЛОВО, 2010. 237 с. 11. Хугаев И.С. Изгой // Дарьял. 2011. № 3. С. 14-51.

12. Хугаев И.С. Осетинская русскоязычная литература: генезис и становление. Автореф. дисс. ... докт. филол. наук. Владикавказ, 2010. 49 с.

13. Хугаев С.3. Нарты Фарнæг // Нарты Фарнæг: роман, радзырдтæ. Дзæуджыхъæу: Ир, 2005. С. 5-335.

14. Шабликова Н.П. Жанровые и стилистические особенности современного американского рассказа // Вестник Костромского университета. 2007. Т. 13. № 4. С. 160-164.

15. Яшуркаев С. Царапины на осколках // Дружба народов, 2010. №6./ http://magazines.russ.ru/druzhba/2010/6/ia12.html (дата обращения 
16.01.2018).

16.Яшуркаев С.Ях. Дневник чеченского писателя / http://tululu.org/ $\operatorname{read53046/4/.~(Дата~обращения~16.01.2018).~}$

17. Gureeva A.A., Novikova E.Y., Mityagina V.A. Guide-interpreter'slang uageidentityasanexcursiondiscoursefactor. // XLinguae. 2016. T. 9. № 2. C. $90-102$.

18. Leontovich O.A. Word and image in search of each other: intersemiotic translation of narratives from an intercultural perspective. ProcediaSocial and Behavioral Sciences. 2015. T. 200. C. 289-295.

19. Leontovich O.A. Where angels fear to tread: communication strategies in an intercultural family. Procedia - Social and Behavioral Sciences. 2014. T. 164. C. 286-291.

20. Novozhilova A.A., Korolkova S.A., Gureeva A.A., Shovgenina E.A., Mityagina V.A. Creating information retrieval competence of future translators: an integrative approach. Mediterranean Journal of Social Sciences. 2015. T. 6. № 6. C. 79-84.

\section{References}

1. Gatsalova L.B., Parsieva L.K. Povtor kak vyrazitel'noe sredstvo yazyka khudozhestvennogo proizvedeniya [Repetition as an expressive means of the literary work]. Vestnik Tomskogo gosudarstvennogo pedagogicheskogo universiteta. 2016. № 11 (176), pp. 101-104.

2. Gatsalova L.B., Parsieva L.K. Sovremennyj russko-osetinskij razgovornik [Contemporary Russian-Ossetian phrasebook]. Vladikavkaz: SOIGSI, 2013. 143 p.

3. Gacalova L.B., Parsieva L.K. Social'no-aksiologicheskie orientiry sovremennogo rossijskogo obshhestva [Social-axiological values of contemporary Russian society]. V mire nauchnyh otkrytij. 2013. № 11.6 (47), pp. 28-31.

4. Martazanov A.M., Martazanova Kh.M. Stanovlenie zhanra povesti $\mathrm{v}$ ingushskoj proze 1950-kh-1960-kh godov [Formation of the short novel genre of the Ingush prose 1950-1960s]. Mir nauki, kul'tury, obrazovaniya. 2016. № 4 (59), pp. 203-205.

5. Martazanova Kh.M. Osmyslenie sud'by tvorcheskoj lichnosti v 
khudozhestvennom mire I. Bazorkina [Interpretation of the creative personality's destiny in the artistic world of I. Bazorkin]. Mir nauki, kul'tury, obrazovaniya. 2015. № 4 (53), pp. 318-320.

6. Martazanova Kh.M. Povest' A. Bokova «Buran» kak znachitel'noe yavlenie ingushskoj prozy 60-kh godov XX veka [The novel Buran by A. Bolov as a significant achievement of the Ingush prose of the 1960s]. Nauchnoe mnenie. 2015. № 11-1, pp. 152-155.

7. Parsieva L.K., Gatsalova L.B. Proizvodnye mezhdometiya: k voprosu o verbalizatsii ehmotsij [Derived interjections: on emotions verbalization]. Baltijskij gumanitarnyj zhurnal. 2016. V. 5. № 3 (16), pp. 66-68.

8. Pastushkova N.A. Ritoriko-stilisticheskie osobennosti ispanskikh sentimental'nykh povestej: ot poehzii k proze [Rhetoric-stylistic features of the Spanish sentimental short novels: from poetry to prose]. Vestnik RGGU. Seriya: Istoriya. Filologiya. Kul 'turologiya. Vostokovedenie. 2010. № 11 (54), pp. 90-96.

9. Pylev A.I. Ahmet Hamdi Tanpinar i ego roman «Spokojstvie». O nekotorykh stilisticheskikh osobennostyakh formy i soderzhaniya proizvedeniya [Ahmet Hamdi Tanpinar and his novel Tranquility. On certain stylistic features of the form and content of the work]. Vestnik Sankt-Peterburgskogo universiteta. Seriya 13. Vostokovedenie. Afrikanistika. 2011. № 4, pp. 51-65.

10.Sitnikov V.P., Shalaeva G.P., Sitnikova E.V. Kto est' kto v mire iskusstva [Who is who in the world of art]. / ed. V.P. Sitnikov. M.: AST, SLOVO, 2010. 237 p.

11.Khugaev I.S. Izgoj [The outcast]. Dar'yal. 2011. № 3, pp. 14-51.

12.Khugaev I.S. Osetinskaya russkoyazychnaya literatura: genezis $i$ stanovlenie [Ossetian Russian-language literature: genesis and formation]. Vladikavkaz, 2010. 49 p.

13.Khugaev S.Z. Narty Farnæg [Narty Farnæg]. Narty Farnoeg: roman, radzyrdtce. Dzæudzhykhæu: Ir, 2005, pp. 5-335.

14. Shablikova N.P. Zhanrovye i stilisticheskie osobennosti sovremennogo amerikanskogo rasskaza [Genre and stylistic features of the modern American story]. Vestnik Kostromskogo universiteta. 2007. V. 13. № 4, pp. 160-164. 
15. Yashurkaev S. Tsarapiny na oskolkakh [Scratches on the shards]. Druzhba narodov, 2010. №6. http://magazines.russ.ru/druzhba/2010/6/ia12.html.

16. Yashurkaev S. Yakh. Dnevnik chechenskogo pisatelya [Yakh. Diary of a Chechen writer]. http://tululu.org/read53046/4/

17.Gureeva A.A., Novikova E.Y., Mityagina V.A. Guide-interpreter's language identity as an excursion discourse factor. XLinguae. 2016. V. 9. № 2, pp. 90-102.

18.Leontovich O.A. Word and image in search of each other: intersemiotic translation of narratives from an intercultural perspective. Procedia - Social and Behavioral Sciences. 2015. V. 200, pp. 289-295.

19.Leontovich O.A. Where angels fear to tread: communication strategies in an intercultural family. Procedia - Social and Behavioral Sciences. 2014. V. 164, pp. 286-291.

20.Novozhilova A.A., Korolkova S.A., Gureeva A.A., Shovgenina E.A., Mityagina V.A. Creating information retrieval competence of future translators: an integrative approach. Mediterranean Journal of Social Sciences. 2015. V. 6. № 6, pp. 79-84.

\section{ДАННЫЕ ОБ АВТОРАХ}

Мартазанов Арсамак Магомедович, доктор филологических наук, ректор, профессор кафедры русской и зарубежной литературы

Ингуиский государственный университет

проспект И.Б. Зязикова, 7, г. Магас, Республика Ингушетия, 386001, Россия

ing_gu@mail.ru

\section{DATA ABOUT THE AUTHOR}

Martazanov Arsamak Magomedovich, Doctor of Philological Sciences, Rector, Professor, Department of Russian and Foreign Literature

Ingush State University

7, I. B. Zyazikov Prospekt, Magas, 386001, The Republic of Ingushetia, Russia

ing_gu@mail.ru

SPIN-code: 2341-8939 